\title{
(c) (1) \\ Acesso à informação na região nordeste: balanço da criação da LAI nos estados e o processo de sua regulamentação no Maranhão
}

Dirlene Santos Barros

Doutora em Ciência da Informação pela Universidade de Brasília (UnB).

Professora Assistente da Universidade Federal do Maranhão (UFMA)

Georgete Rodrigues Medleg

Doutora em História pela Université de Paris IV, Sorbonne. Professora Associada I da Universidade de Brasília do Curso de graduação em Arquivologia e do Programa de Pós-graduação em Ciência da Informação da Faculdade de Ciência da Informação. Bolsista da Fundação de Amparo à Pesquisa e ao Desenvolvimento Científico e Tecnológico do Maranhão (FAPEMA)

http://dx.doi.org/10.1590/1981-5344/2581

A Lei de Acesso à Informação (LAI) tem natureza mista: é de caráter federativo e é lei da federação, indicando, assim, alguns procedimentos a serem observados pelos estados em sua regulamentação. Este artigo analisa a regulamentação da $L A I$ nos estados da região Nordeste, com ênfase no estado do Maranhão. Para tanto, realizamos um levantamento bibliográfico e documental com abordagem qualitativa. Desenvolvemos, ainda, a exploração dos portais dos governos estaduais, da CGU e links ou outros sites que indicassem informações sobre a LAI. A base de análise dos dados foram as diretrizes preconizadas pela $L A I$ nacional e seu decreto de regulamentação - Decreto n. 7.724/2012. Os resultados demonstram que as $L A I$ dos estados nordestinos contemplam as transparências ativa e passiva, tal como preconizada na lei e no decreto que as regulamentam, além da autoridade de monitoramento e de classificação. No caso específico do Maranhão, apesar de algumas 
lacunas, há um esforço em garantir o acesso à informação.

Palavras-chave: Lei de Acesso à Informação (LAI). Leis de Acesso à Informação na região Nordeste. Lei de acesso à informação no Estado do Maranhão.

\section{Access to information in the northeast: balance sheet of LAI creation in the states and the process of its regulation in Maranhão}

Law on Access to Information (LAI) has dual nature: it is of federal character and is law of the federation, indicating some procedures to be followed by the states in their regulation. This article analyzes the regulation of LAI in the states of the Northeast region, with emphasis on the state of Maranhão. Thus, we conducted a bibliographical and documentary survey with a qualitative approach. We also developed the exploitation of portals of state governments, the CGU and links or other sites that indicate information about the LAI. Analysis of the data base was the guidelines recommended by the National $L A I$ and its regulatory decree - Decree n. 7724/2012. The results demonstrate that the $L A I$ of the northeastern states include the active and passive transparency, as required by law and the decree that regulates them, as well as monitoring and classification authority. In the specific case of Maranhão, although some gaps, there is an effort to ensure access to information.

Keywords: Law on Access to Information (LAI); Laws on Access to Information in northeast region; Law on Access to Information in Maranhão.

Recebido em 14.09.2015 Aceito em 13.07.2017

\section{Introdução}

Com a aprovação da Lei de Acesso à Informação (LAI), no 12.527/2011 (BRASIL. Presidência da República, 2011a), a percepção de resistência à regulamentação do acesso à informação pelos estados da federação brasileira tem nos instigado a pesquisar o que tem conduzido a essa prática. Tais pesquisas, é oportuno destacarmos, são ampliadas com 
os estudos desenvolvidos para a construção da nossa tese em Ciência da Informação sobre a LAI no Maranhão.

Essa constatação reflete claramente os limites e as possibilidades do processo de debate e implementação da LAI na região Nordeste e, especificamente, no estado do Maranhão, governado de 2009 a 2014 por Roseana Sarney do Partido do Movimento Democrático Brasileiro do Maranhão (PMDB/MA), datas que coincidem com o envio, ao Congresso Nacional, do projeto de lei $(P L)$ da LAI pelo Executivo federal e o aniversário de dois anos da entrada em vigor da referida lei. Nesse período, houve tímida divulgação da lei pelos meios de comunicação maranhense ${ }^{1}$, bem como resistência ou silêncio oficial em sancionar a LAI estadual $^{2}$. Esse contexto é relevante para corroborar a afirmação de que os estados com menor nível de transparência encontram-se nas regiões Norte e Nordeste, conforme aponta a Escala do Brasil Transparente (EBT), desenvolvida pela Controladoria Geral da União (CGU), monitoramento que traduz um esforço da CGU sobre a criação e implementação da LAI nos estados brasileiros. ${ }^{3}$

Este artigo parte de uma pesquisa de doutorado em andamento em Ciência da Informação e apresenta os resultados sobre a análise da regulamentação da LAI nos estados da região Nordeste, com ênfase no processo de criação desta lei no estado do Maranhão, tendo como base as diretrizes preconizadas pela LAI nacional e seu decreto de regulamentação - Decreto no 7.724/2012 (BRASIL. Presidência da República, 2012) -, bem como destaca as peculiaridades pertinentes a cada LAI estadual. A metodologia se configurou com a exploração dos portais dos governos estaduais, da CGU e links ou outros sites que indicassem informações sobre a LAI com vistas a elaborar um quadro panorâmico sobre a regulamentação. Nosso corpus de análise compreende todos os estados do Nordeste, ou seja, Ceará, Sergipe, Pernambuco, Bahia, Alagoas, Paraíba, Piauí, Rio Grande do Norte e Maranhão. Este último estado foi objeto de uma análise individualizada por se constituir no campo empírico da tese em elaboração. O critério definido para o levantamento das LAI estaduais da região Nordeste foi demográfico e socioeconômico. Conforme estimativa do Instituto Brasileiro de Geografia e Estatística (IBGE), no ano de 2014, a população brasileira era de 202 milhões de habitantes, sendo 56.186.190 milhões residentes na região Nordeste. ${ }^{4}$

${ }^{1}$ BARROS, D. S.; RODRIGUES, G. M. Os caminhos da (des)informação no jornal O Estado do Maranhão: o papel da mídia na divulgação da Lei de Acesso à Informação Pública. In: ENCONTRO NACIONAL DE PESQUISA EM CIÊNCIA DA INFORMAÇÃO, 14., Florianópolis, 2013. Anais... Florianópolis: ANCIB, 2013. Disponível em: <http://enancib.sites.ufsc.br/index.php/enancib2013/XIVenancib/paper/viewFile/545/468>. Acesso em: 2 ago. 2015.

${ }^{2}$ Apenas em 20 de outubro de 2014, a então governadora do Maranhão Roseana Sarney (PMDB) encaminha à Assembleia Legislativa do Maranhão o Projeto de Lei no 200, que dispõe sobre o acesso à informação no Maranhão. Isso depois de três anos de sanção da LAI nacional e depois de perder as eleições estaduais. (MARANHÃO, 2014). Disponível em: <http://www.al.ma.leg.br/diarios/arquivos/22102014-1468753316diario.pdf >. Acesso em: 22 out. 2014.

${ }^{3}$ A CGU tem desenvolvido várias iniciativas para implementação e monitoramento da LAI, como o Programa Brasil Transparente (2013), a Escala Brasileira de Transparência (2015), Serviço de Informação ao Cidadão (2011), Cursos presencias e a distância sobre a LAI dentre outras (conferir informações em: <http://www.cgu.gov.br/sobre/acoes-e-programas>). Acesso em: 10 ago.2015.

4 Demograficamente, esse número é significativo comparado, por exemplo, à população das regiões CentroOeste, Norte e Sul do País. Das quinze cidades mais populosas brasileiras, quatro estão no Nordeste: Salvador (terceira posição, 2.902.927 milhões); Fortaleza (quinta posição, 2.571 .896 milhões); Recife 
Os indicadores levantados na pesquisa foram: disponibilização da lei nos sites pesquisados; período de regulamentação da LAI ou Decreto; regulamentação e existência do SIC; determinação de uma autoridade de classificação das informações sigilosas e de monitoramento da LAI. Tendo em vista que o decreto que regulamentou a LAI introduziu o conceito de "transparência ativa" (publicação de informações pelos órgãos públicos independentemente de demandas), esse aspecto também será considerado na pesquisa. Os dados foram analisados conforme as diretrizes preconizadas pela LAI e pelo seu decreto de regulamentação a partir de uma abordagem qualitativa.

Assim, fazemos, inicialmente, uma abordagem histórica sobre a configuração da LAI brasileira e a sua implementação no cenário nacional. Em seguida, apresentamos a configuração da LAI nos estados do Nordeste com ênfase no estado do Maranhão, seguido das considerações finais.

\section{A Lei de Acesso à Informação brasileira: Do projeto de Lei do Executivo federal à sua implementação}

Concebemos a LAI sob um olhar plural: histórico, social, político e jurídico. Ela é um mecanismo positivado de diálogo entre a Administração Pública e a sociedade. Fortalece o direito do cidadão de buscar informação, de ser informado e de informar com vistas a, dentre outros, efetivar o direito à verdade e à memória. ${ }^{5}$ Possibilita, ainda, ao cidadão ser um partícipe no monitoramento, na avaliação e no controle social da ação e da tomada de decisões pelo Estado, que, a nosso ver, desemboca na legitimidade, qualidade e eficiência da gestão pública. Por outro lado, adotamos o pressuposto de que a LAI foi possível no contexto da redemocratização pós-ditadura militar e da promulgação da Constituição Federal de 1988 (BRASIL. Constituição, 1988), onde o direito à informação afirma o status de direito fundamental, conforme o art.50, inc. 33, da CF/1988, (BRASIL. Constituição, 1988) ${ }^{6}$.

Contudo, apesar dessa ruptura com o regime do segredo alimentado, principalmente, por legislações anteriores à CF/1988, bem como pelo período do regime militar -, o Brasil não possuía um diploma

(nona posição, 1.608.488 milhões); e São Luís (décima quinta posição, 1.064.197 milhões) (IBGE, 2014). Além do crescimento populacional, o Nordeste teve em 2014 um crescimento moderado, reflexo da crise nacional. No entanto, teve o maior aumento na receita nominal em comparação às outras regiões do País: $3,8 \%$. Esse crescimento repercutiu, favoravelmente, no comportamento de outros serviços $(9,7 \%)$ e serviços auxiliares dos transportes e correios (7,4\%) (BRASIL, 2015). Na contramão desses dados, a região nordeste concentra grandes latifundiários, seca natural constante, número expressivo de analfabetismo (27,2\%, em 2013), segundo o IBGE (2014), além da marcante presença de oligarquias, como Sarney, no Maranhão; Calheiros e Collor, em Alagoas; Alves, Malha e Rosado, no Rio Grande do Norte; Magalhães, na Bahia; Jereissati e Accioly, no Ceará.

5 Não é por acaso que a Lei no 12.528, criando a Comissão Nacional da Verdade foi promulgada na mesma data da LAI (BRASIL. Presidência da República, 2011).

6 É oportuno destacar que, mesmo com a redemocratização do Brasil em 1988, ainda continuamos com algumas leis no formato da ditadura. Como exemplo temos a condenação do Brasil pela Corte Americana de Direitos Humanos no caso da Guerrilha do Araguaia. Este foi um dos fatos marcantes para a promulgação da LAI brasileira, no 12.527/2011 (SALES, 2014). Anterior a isso, houve as pressões por parte da Organização das Nações Unidas para a Educação, a Ciência e a Cultura, Banco Mundial dentre outros organismos multilaterais, que passaram a exigir mais transparência sobre a movimentação financeira do País. 
legal que regulamentasse o cumprimento desse direito fundamental. Isso, para Bertazzi (2011, p. 26), limitava "[...] em demasia o exercício das garantias enumeradas no texto constitucional $[\ldots]^{\prime \prime}$. Esses limites eram, de certa forma, tributários do processo mesmo de redemocratização e das forças políticas que concorreram para o fim do regime militar. Nesse sentido, muitos movimentos da sociedade civil organizada vinham pressionando os sucessivos governos pós-ditadura militar a abrirem os arquivos daquele período, 0 que resultara apenas em pequenas modificações nas leis de acesso (RODRIGUES, 2011). Assim, podemos afirmar que essas manifestações internas, associadas às tendências internacionais pela criação de leis de acesso à informação, impulsionaram o processo de articulação, no interior do governo federal, para a criação do $\mathrm{PL}$, que deu origem à LAI brasileira (RODRIGUES, 2013). Os debates ocorridos em 2005 no Conselho da Transparência Pública e do Combate à Corrupção (CTPCC) ${ }^{7}$ da CGU, corroboram, em parte, essa tese.

Em 2006 foi elaborado um texto preliminar com a participação de vários representantes do governo e da sociedade civil organizada e, em 2009, encaminharam-no à Casa Civil da Presidência da República, onde foi analisado, revisto e apresentado pelo Poder Executivo federal à Câmara dos Deputados (CD) em forma do PL no 5.228/2009 (BRASIL. Câmara dos Deputados, 2009). Este PL tramitou na CD conjuntamente com o PL no 219/2003 (BRASIL. Câmara dos Deputados, 2003), de autoria do deputado Reginaldo Lopes do Partido dos Trabalhadores de Minas Gerais (PT/MG), por convergirem sobre o mesmo assunto.

Para julgamento do seu mérito, o PL no 5.528/2009 deveria ser analisado por três comissões permanentes. Todavia, devido tramitar em caráter de urgência, criou-se uma Comissão Especial que agregou as funções das três referidas Comissões (CUNHA FILHO; XAVIER, 2014). Após aprovação do PL nessa Comissão, o Deputado Reginaldo Lopes (PT/MG), em conjunto com o presidente da Comissão, José Genuíno (PT/SP), apresentaram o PL ao presidente da CD, Michel Temer (PMDB/SP), para votação no Plenário, onde foi aprovado, no dia 13 de abril de 2010. Em seguida, foi encaminhado ao Senado Federal (SF), numerado como PL da Câmara no 41/2010 (BRASIL. Câmara dos Deputados, 2010), cuja relatoria ficou com o senador Fernando Collor de Mello do Partido Trabalhista Brasileiro de Alagoas (PTB/AL). No SF, o PLC passou por quatro Comissões: Constituição e Justiça; Direitos Humanos e Legislação Participativa; Ciência, Tecnologia, Inovação, Comunicação e Informática e Comissão de Relações Exteriores e Defesa Nacional, sendo retido por mais tempo nesta última, por ação do relator que apresentou um substitutivo, por meio da Emenda n. 5, que foi rejeitada por 43 votos contra e 9 favoráveis (BRASIL. Presidência da República, 2011). Esse substitutivo representava a posição dos senadores Fernando Collor e José Sarney (PMDB/AP), este último então presidente do SF, serem contrários

${ }^{7}$ O CTPCC foi criado pelo Decreto no 4.923 de 18 de dezembro de 2003 (BRASIL. Presidência da República, 2003), como órgão colegiado e consultivo vinculado à CGU, com a "[...] finalidade de sugerir e debater medidas de aperfeiçoamento dos métodos e sistemas de controle e incremento da transparência na gestão da administração pública, e estratégias de combate à corrupção e à impunidade." 
ao prazo máximo de cinquenta anos estabelecidos para o acesso aos documentos sigilosos. Ambos defendiam que esse prazo fosse prorrogado por várias vezes ${ }^{8}$. Segundo o senador Collor de Mello:

Defendo a abertura recente dos documentos, agora, os documentos históricos que fazem parte da nossa história diplomática, da nossa história do Brasil, que tenham articulações com Rio Branco teve que fazer muitas vezes, não podemos revelar esses documentos se não vamos abrir feridas, afirmou Sarney (BONI, 2011, s.p.).

Assim, somente no dia 25 de outubro de 2011 é que o plenário do SF aprova o projeto, com o voto contrário apenas do senador Fernando Collor.

Depois desse debate no Legislativo, houve a promulgação da LAI conjuntamente com a Lei no 12.528 (BRASIL. Presidência da República, 2011b), que criou a Comissão Nacional da Verdade (CNV). Não se trata de uma mera coincidência, pois ambas convergem para o mesmo fim (NUNES, 2014), conforme evidenciamos no pronunciamento da presidente Dilma Rousseff:

O sigilo não oferecerá, nunca mais, guarida ao desrespeito aos direitos humanos no Brasil. Esta é uma importante conexão, uma conexão decisiva com a lei que cria a Comissão da Verdade. Uma não existe sem a outra, uma é pré-requisito pra outra, e isso lançará luzes sobre períodos da nossa história que a sociedade deve conhecer [...] (ROUSSEFF, 2011, s.p.). ${ }^{9}$

É importante frisarmos que após a aprovação da LAI, conforme referencia Indolfo (2013), além da CGU, outros órgãos da Administração Pública se organizaram para implementar a LAI com a criação de grupos de trabalho por alguns ministérios, bem como as propostas aprovadas e as moções recomendadas pela plenária da I Conferência Nacional de Arquivos (Conarq), realizada em novembro de 2011 sobre o papel das instituições arquivísticas nesse processo.

Desse modo, a LAI no Brasil foi possível, também, pelas reinvindicações do direito à verdade e à memória. A LAI contou com forte participação da sociedade civil organizada, como jornalistas, familiares das vítimas de desaparecidos políticos e de acadêmicos, assim como contou com a legitimação das decisões tomadas pela Corte Americana de Direitos Humanos e do Judiciário nacional. Ela instrumentaliza, assim, um dos

\footnotetext{
${ }^{8} \mathrm{O}$ posicionamento dos senadores Fernando Collor (PTB/AL) e José Sarney (PMDB/AP) foi veiculado em várias reportagens de importantes meios de comunicação em nível nacional, por exemplo: "ESCANDÂLO no Congresso: Sarney (PMDB-AP) e Collor (PTB-AL) defendem sigilo eterno para documentos públicos.

Disponível em: <http://noticias.uol.com.br/politica/escandalos-no-congresso/sarney-pmdb-ap-e-collor-ptb-al-defendem-sigiloeterno-para-documentos-publicos.htm>." Acesso em: 20 jun.2011. "GUERREIRO, Gabriela. Collor defende sigilo eterno como 'questão de Estado'. Folha, São Paulo, Poder, 16 jun. 2011. Disponível em: <http://www1.folha.uol.com.br/poder/2011/06/930868-collor-defende-sigilo-eterno-como-questao-deestado.shtml?mobile>. Acesso em: 20 out.2011.

${ }^{9}$ Discurso proferido pela presidenta da República, Dilma Rousseff, na solenidade de sanção do projeto de lei que garante o acesso à informação pública e ao projeto de lei que cria a Comissão Nacional da Verdade, no Palácio do Planalto, no dia 18 de novembro de 2011. Disponível em: <http://www2.planalto.gov.br/acompanheo-planalto/discursos/discursos-da-presidenta/discurso-da-presidenta-da-republica-dilma-rousseff-durante-cerimonia-desancao-do-projeto-de-lei-que-garante-o-acesso-a-informacoes-publicas-e-do-projeto-de-lei-que-cria-a-comissao-nacionalda-verdade>. Acesso em: 20 nov. 2011.
} 
direitos fundamentais do cidadão, o direito de acesso à informação. Atua como um mecanismo para o exercício de outros direitos, pois ela redimensiona a transparência pública, a legitimidade do Estado junto à sociedade, bem como o direito à saúde, ao meio ambiente, à educação, à moradia, dentre outros. Nessa mão dupla, não podemos ignorar a obrigação do Estado no processo de implantação da LAI por meio da disponibilização, por exemplo, de instrumentos que disciplinam tal consecução, nem da sociedade através da internalização desse direito.

O processo de implementação da LAI no Executivo federal no Brasil teve um prazo exíguo de seis meses e coube à CGU o papel central para tal função ${ }^{10}$. Com essa finalidade, a CGU desenvolveu várias ações visando ao treinamento dos servidores públicos. ${ }^{11}$ A CGU promove ainda ações de capacitação direcionadas aos estados e municípios e, de acordo com o último levantamento feito pela CGU, já há a adesão de mais de mil e quinhentos municípios em todo o Brasil (BRASIL. Controladoria Geral da União, 2015).

Destarte, vemos que a LAI tem potencial para promover uma mudança na cultura organizacional dos órgãos públicos, que contempla desde a conscientização do agente público de que ele não é o detentor da informação, mas, sim, o cidadão, até a disponibilização de conjuntos documentais considerados sigilosos, como os da Guerrilha do Araguaia e do período da ditadura. Entretanto, não podemos negligenciar os aspectos que dificultam a implementação da LAI, tais como: o desafio tecnológico, principalmente, para os pequenos municípios, no sentido não só de consolidar os dados governamentais para serem transmitidos para o site do governo, mas, também, no alcance da banda larga nos lugares mais remotos do Brasil, embora $49,4 \%$ da população brasileira tenha acesso à internet, conforme a Pesquisa Nacional por Amostra de Domicílios (PNAD) de 2013. (INSTITUTO BRASILEIRO DE GEORGRAFIA E ESTATISTICA - IBGE, 2013).

Outro aspecto positivo da LAI é que ela, de certa forma, imprime aos órgãos da administração pública a necessidade de desenvolverem a gestão documental, devido à obrigatoriedade de disponibilizar a informação em tempo determinado. Todavia, vemos que a organização dos arquivos se constitui um dos grandes obstáculos da implementação da LAI e que pouco se fez nessa direção, conforme os relatórios sobre a LAI no âmbito do executivo federal (BRASIL. Controladoria Geral da União, 2013; 2014).

O próprio texto da LAI nacional não contempla diretamente aspectos acerca dos arquivos e da gestão documental, ainda que as informações objeto da LAI - e do decreto que a regulamenta - essencialmente de caráter arquivístico. Assim, apesar do Decreto no 7.728/2012, em seu art.

\footnotetext{
${ }^{10}$ Exemplos como as Leis de Acesso à Informação do Reino Unido aprovada em 2000, mas que entrou em vigor somente em 2005; da Jamaica, sancionada em 2002, e passou a vigorar a partir de 2004; do Japão, que entrou em vigor em 2001, embora tenha sido aprovada em 1999 (MENDEL, 2009).

11 Dentre outras ações, estabeleceu os procedimentos e estruturas dos canais de acesso à informação, por exemplo, o Sistema de Informação ao Cidadão (SIC) - transparência passiva; disponibilizou guias para orientação sobre a transparência ativa; desenvolve monitoramento e avaliação da LAI no âmbito do Executivo federal e elabora relatórios sobre a LAI (BRASIL. Presidência da República, 2011).
} 
71, evidenciar que "[...] os órgãos e Entidades adequarão suas políticas de Gestão da informação, promovendo os ajustes necessários aos processos de registro, processamento, trâmite e arquivamento de documentos e informações.", não há menção direta a respeito da forma de gestão desses documentos (BRASIL. Presidência da República, 2012).

O que apreendemos, assim, é que a gestão documental precisa ser implementada a fim de disponibilizar, de forma prática e eficiente, as informações solicitadas, afinal "[...] o fundamento da LAI é a primazia da transparência do Estado sobre a opacidade [...]" (JARDIM, 2013, p. 387), o que favorece a tomada de decisão. Isso proporciona a interação entre as classes, entre os direitos do sujeito e os da sociedade e a configuração das tomadas de decisão ordinária.

Dessa forma, considerando que o texto da LAI compromete também os estados e municípios, e de acordo com os objetivos deste artigo, abordaremos, na seção seguinte, como os estados do nordeste estão criando e implementando as suas respectivas LAI.

\section{A implementação da LAI na região Nordeste}

A região Nordeste, até julho de 2015, teve 33\% de adesão dos seus municípios ao Programa Brasil Transparente da CGU (BRASIL. Controladoria Geral da União, 2015). As capitais São Luís, Maceió e Aracaju ainda não possuem a regulamentação da LAI na região Nordeste. Lembrando que em estudo publicado em 2014, com base em levantamento feito em janeiro de 2013, Moreira, Cassiano e Schmidt (2014), constataram que a LAI estava regulamentada em 12 Estados, dentre eles quatro do nordeste: Bahia, Ceará, Paraíba, Pernambuco. Os outros estados identificados foram: Rio de Janeiro, Roraima, Rio Grande do Sul, Santa Catarina e São Paulo. Dez capitais também foram arroladas: Rio Branco, Manaus, Brasília, Vitória, Belo Horizonte, Campo Grande, Belém, Rio de Janeiro, Florianópolis e São Paulo. Ou seja, do NE, em 2013, apenas uma capital possuía a lei.

Em 2015, no que concerne aos estados do nordeste objeto de nossa pesquisa, a situação se configurava da seguinte forma: Ceará - LAI n. 15.175, sancionada em 28 de junho de 2012. No ranking da EBT/CGU, a LAI do Ceará alcançou o primeiro lugar (nota 10,0); Sergipe ${ }^{12}$ - Instrução Normativa Conjunta no 001 de 12 de setembro de 2012, entre a Procuradoria Geral do Estado, a Controladoria Geral do Estado e o Governo do Estado, representado pela Casa Civil. Está em quarto lugar na ETB/CGU (nota 9,31); Pernambuco - regulamentou a LAI por meio da Lei n. 14.804 e o Decreto 38.787, ambos de 29 de outubro de 2012. Ocupa a décima primeira colocação na EBT/CGU (nota 8,61); Bahia - Lei estadual n. 12.618, de 28 de dezembro de 2012. No ranking da EBT/CGU

\footnotetext{
${ }^{12}$ O projeto de lei para regulamentação da LAI no estado de Sergipe foi enviado em maio de 2012 e ainda está tramitando na Assembleia Legislativa do Estado. Conforme informação da SERGIPE. Controladoria Geral do Estado. Lei de Acesso à Informação em SE revela índices positivos. Aracaju, 2014. Disponível em: http://www.cge.se.gov.br/index.php/noticias/3052-lei-de-acesso-a-informacao-em-se-revela-indices-positivos. Acesso em: 23 agosto 2015 e pesquisa realizada no site de transparência pública do governo do estado de Sergipe. Disponível em: <http://www.transparenciasergipe.se.gov.br/setp/index.html>.
} 
vem logo após Pernambuco, ou seja, em décimo segundo lugar (nota 8,33); Alagoas - Decreto n. 26.320, de 13 de maio de 2013. Ocupa na EBT o décimo terceiro lugar (nota 7,78); Paraíba - Decreto n. 33.050, de 25 de junho de 2012. Na EBT está na décima quarta colocação (nota 7,78); Piauí -Decreto n. 15.188, de 22 de maio de 2013. Ocupa a décima sexta posição na EBT (nota 6,67); Rio Grande do Norte - Lei n. 9.963, de 27 de julho de 2015. Ocupou o último lugar na EBT (nota 0,00).

Em termos de transparência ativa, as LAI dos oito estados da região Nordeste a contemplam: Ceará (Art. 11) - Portais da Transparência, Sítios Institucionais, Audiências ou Consultas Públicas; Sergipe (Art. 15) - Portal de Transparência; Pernambuco (Art. 40) - Portal da Transparência do estado de Pernambuco, sítios dos órgãos governamentais, sistema de Ouvidoria do estado de Pernambuco; Bahia (Art. 60) - site da Ouvidoria Geral do estado, Central de Atendimento da Ouvidoria Geral do estado (telefone), rede de Ouvidorias Especializadas do estado ou, onde não houver, pelo Serviço de Informações instituído pelos próprios órgãos ou entidades; Alagoas (Art. 60) - site dos órgãos e entidades estaduais; Paraíba (Art. 70) - Sites na internet dos órgãos e entidades; Piauí (Art. 70) - Sites dos órgãos e entidades; Rio Grande do Norte (Art. 70) - Portal de Transparência do estado do Rio Grande do Norte.

A solicitação de informação feita pelo cidadão, ou seja, a transparência passiva também é desenvolvida pelos aludidos estados por meio do Sic físico e pelo e-Sic. Além desses mecanismos da transparência passiva, o estado do Ceará conta ainda com a Central de Atendimento Telefônico da Ouvidoria e com o Sistema de Ouvidoria (Art. 12) e, no estado da Paraíba, essa solicitação é facultada pelo telefone (Art. 9).

Outro aspecto contemplado em conformidade com a LAI nacional é a autoridade de monitoramento e a instância recursal existente nas LAI estaduais da região referenciada. Entretanto, quando nos reportamos à indicação de uma autoridade para a classificação das informações no grau sigiloso, o estado de Sergipe é o único que não a menciona. Dentre as lacunas evidenciadas nas oito regulações estaduais da região nordeste, há ausência dos aspectos mais diretos sobre os arquivos públicos, o documento de arquivo e a gestão documental. Esse cenário é reflexo da LAI nacional, como já mencionado.

Todavia, localizamos nas LAI dos estados do Rio Grande do Norte, Piauí, Paraíba e Bahia uma correlação com o arquivo quando abordam a concepção de tratamento da informação, mencionando algumas atividades da gestão documental, como produção, recepção, classificação, dentre outras.

Apesar da existência de leis de acesso à informação, alguns estados do nordeste têm sido acusados de criarem leis em desacordo com a LAI nacional, conforme reportagens veiculadas pela mídia: Ceará - responde a uma Ação Direta de Inconstitucionalidade (ADI) pelo procurador-geral da 
República, Rodrigo Janot, contra alguns de seus dispositivos ${ }^{13}$; Sergipe - a CUT solicita ação contra os Poderes Executivo e Legislativo estadual, e também do Tribunal de Contas do Estado de Sergipe (TCE/SE) e da Defensoria Pública do Estado ${ }^{14}$; Alagoas - o Ministério Público Estadual ajuizou uma ação civil pública contra a Assembleia por falta de transparência no orçamento ${ }^{15}$; Paraíba - 33 prefeituras são multadas pelo descumprimento da $\mathrm{LAI}^{16}$; Piauí - de acordo com reportagem veiculada no dia 7 de maio de 2015, 86\% dos municípios descumprem a LAI $^{17}$ e outra matéria divulgada pelo Agoraed, no dia 15 de junho de 2015, afirma que a maioria das Prefeituras do Piauí não divulga os dados para a transparência. ${ }^{18}$

\subsection{A LAI no estado do Maranhão}

De 2012 a 2014, não houve manifestação por parte do governo estadual no processo de regulamentação da LAI no Maranhão. Em 20 de outubro de 2014, a então governadora, Roseana Sarney (PMDM/AP), encaminhou à Assembleia Legislativa o PL no 200/2014 sobre o acesso à informação no aludido estado, constituído por quarenta e seis artigos (MARANHÃO, 2014). Na mensagem a governadora afirma:

Reconhecido como um direito humano fundamental, o acesso à informação pública está inscrito em diversas convenções e tratados internacionais assinados pelo Brasil. Ao contemplá-lo, o País integrase, ainda, a um amplo grupo de nações que reconhece ser a informação sob guarda do Estado um bem público [...] (MARANHÃO, 2014, p. 16). ${ }^{19}$

Observamos que Roseana Sarney declara a importância do preceito do acesso à informação no fortalecimento dos sistemas democráticos, favorecendo a boa gestão pública. No entanto, o referido PL só foi encaminhado após três anos de governo e três de regulamentação da LAI em âmbito nacional. Urge enfatizar que o envio desse PL ocorreu logo após o candidato do grupo Sarney, Edison Lobão Filho (PMDB/MA), perder as eleições governamentais para Flávio Dino do Partido Comunista do

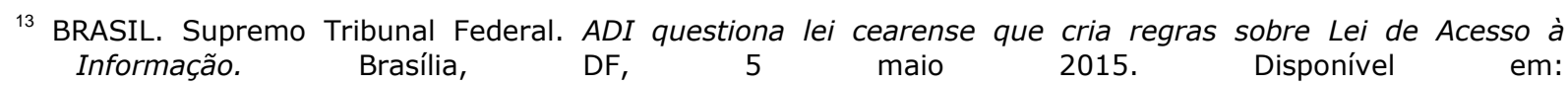
<http://www.stf.jus.br/portal/cms/verNoticiaDetalhe.asp?idConteudo=290799>. Acesso em: 12 ago.2015.

${ }^{14}$ CUT PEDE ação do MPF para que Sergipe cumpra Lei da Transparência. News, 12 dez. 2014. Disponível em: $<$ http://www.f5news.com.br/318173 cut-pede-acao-do-mpf-para-que-sergipe-cumpra-lei-da-transparencia-.html>. Acesso em: 10 ago. 2015.

${ }^{15}$ MPE/AL AJUIZA nova ação contra a Assembleia por falta de transparência nas contas do Legislativo. 21 jan. 2015. Disponível em: <http://www.ampal.com.br/noticias/690/mpe-al-ajuiza-nova-acao-contra-a-assembleia-por-faltade-transparencia-nas-contas-do-legislativo>. Acesso em: 10 ago. 2015.

16 TCE MULTA 33 prefeitos por não cumprimento da Lei de Acesso à Informação. RadarPB, 26 fev. 2015. Disponível em: <http://radarpb.com.br/arquivo/tce-multa-33-prefeitos-por-nao-cumprimento-de-lei-de-acesso-ainformacao/>. Acesso em: 10 ago. 2015.

17 86\% DOS MUNICÍPIOS do Piauí descumprem a Lei de Acesso à Informação. Cidade Verde, Teresina, Política, 7 maio 2015. Disponível em: <http://cidadeverde.com/noticias/192115/86-dos-municipios-do-piaui-descumprem-leide-acesso-a-informacao>. Acesso em: 10 ago. 2015.

18 MAIORIA dos municípios do Piauí não divulga os dados para transparência. Agoraed, Teresina, Política, 15 jun. 2015. Disponível em: <http://www.agoraed.com/portalnovo/cover.php?pg=shmt\&id=25124>. Acesso em: 10 ago. 2015.

19 Mensagem no 076/2014 encaminhada pela governadora Roseana Sarney no dia 22 de outubro de 2014 à Assembleia Legislativa do Maranhão (MARANHÃO, 2014). 
Brasil (PCdoB/MA). ${ }^{20}$ Pela falta de quórum para a Ordem do Dia, o PL enviado por Roseana Sarney não foi votado. Tendo em vista que havia outros $\mathrm{PL}$, os deputados estaduais de oposição os consideraram inadequados, pois, segundo eles, teriam consequências, direta ou indiretamente, para o governo seguinte (MADEIRA, 2014).

No dia 13 de março de 2015, Flávio Dino, governador eleito em 2014, encaminhou, em regime de urgência, o PL no 040/2015 à Assembleia Legislativa do Estado (MARANHÃO, 2015). Na Mensagem no 034/2015, Flávio Dino enfatiza que "[...] o Estado do Maranhão está em mora com a sua obrigação constitucional há mais de três anos na garantia desse direito básico do cidadão." (MARANHÃO, 2015, p. 4). ${ }^{21}$ O referido $\mathrm{PL}$, constituído por trinta e quatro artigos dispostos em oito capítulos, recebeu parecer favorável das comissões técnicas do Legislativo estadual, sendo aprovado no dia 19 pelo Plenário. A sanção da LAI maranhense ocorreu em uma solenidade no dia 20 de março, com a presença de Valdir Simão, Ministro-Chefe da CGU. Na ocasião, foi lançado o portal de transparência do governo, sinalizando a adesão do governo do estado ao Programa Brasil Transparente da CGU. Na avaliação da EBR/CGU, a LAI maranhense, alcançou o vigésimo quinto lugar com a nota 2,22 . Dentre os pontos negativos avaliados estão a ausência da regulamentação da LAI estadual na página do ente governamental, divulgação do SIC presencial e inexistência do e-SIC.

$\mathrm{Na}$ sua estrutura, a LAI maranhense contempla, assim como as outras LAI dos estados da região, a documentação de arquivo em seu art. 50, ao abordar o tratamento da informação, as características dos documentos de arquivo como autenticidade, integridade, primariedade dentre outros (MARANHÃO, 2015). Outra menção ao arquivo está presente no art. $8^{\circ}, \S 3^{\circ}$, que se reporta à necessidade de comunicação entre o SIC e setores pertinentes:

Para o pleno desempenho de suas atribuições, os Serviços de Informação ao Cidadão - SIC deverão manter intercâmbio permanente com os serviços de protocolo e arquivo, buscar informações junto aos gestores de sistemas informatizados e bases de dados, inclusive de portais e sítios institucionais e atuar de forma integrada com os serviços de ouvidoria. (MARANHÃO, 2015, s.p., grifo nosso).

Assim, houve, mesmo que minimamente - pois não aborda concepções sobre os arquivos públicos e a gestão documental -, uma ampliação da inserção do arquivo na LAI maranhense ao relacioná-lo ao SIC no provimento de informações para o acesso pelo cidadão, em consonância ao art. 71 do Decreto no 7.724/2012 (BRASIL. Presidência da

\footnotetext{
${ }^{20}$ Entretanto, mesmo que esse PL fosse aprovado, fato que não aconteceu, ele só entraria em vigor no governo de Flávio Dino (PCdoB), gestão 2015/2018.

${ }^{21}$ O estado do Maranhão respondia a um Mandado de Injunção sob o no 13.173/2014 no Tribunal de Justiça do estado pela sua omissão na regulamentação da LAI. O Mandado foi impetrado em março de 2014 . $\mathrm{Na}$ época do envio do PL 040/2015, o mandado aguardava julgamento, sendo arquivado em julho de 2015. Informação disponível em: MARANHÃO. Tribunal de Justiça do Maranhão. Mandato de Injunção no13.173/2014. São Luís, 2014. Disponível em:<http://www.tjma.jus.br/>. Acesso em: 2 ago.2015.
} 
República, 2012), sobre a adequação às políticas de gestão da informação.

Quanto à Transparência Ativa, esta é contemplada nos arts. 40, $5^{\circ} \mathrm{e}$ 70 da LAI no 10.217/2015 (BRASIL. Presidência da República, 2015). Já a Transparência Passiva encontra-se nos arts. $5^{\circ}, 70$ e $8^{\circ}$, onde se determina a criação do SIC físico, quanto o e-Sic, destacando, no $\S 4^{\circ}$ do art. $8^{\circ}$, a ampla divulgação desse serviço "[...] Os Serviços de Informações ao Cidadão - SIC, independentemente do meio utilizado, deverão ser identificados com ampla visibilidade." (MARANHÃO, 2015, s.p.). A autoridade de monitoramento é determinada pelos secretários de estado ou autoridades máximas de cada órgão ou das entidades da gestão pública direita ou indiretamente. Tal designação tem um prazo máximo de sessenta dias (art. $8^{\circ}$ ). A Lei preconiza, ainda, a instância recursal, que cabe à Secretaria de Estado de Transparência e Controle do Poder Executivo e à Comissão Mista de Reavaliação de Informações (arts. 11, 13 e 14).

Conforme art. 20 da lei, a classificação das informações quanto ao sigilo nos graus ultrassecreto, secreto e reservado é competência:

I - no grau de ultrassecreto, das seguintes autoridades:

a) Governador do Estado;

b) Presidente da Assembleia Legislativa;

c) Presidente do Tribunal de Justiça;

d) Presidente do Tribunal de Contas do Estado;

e) Procurador-Geral de Justiça.

II - no grau de secreto, das autoridades referidas no inciso I, dos secretários de estado, titulares de autarquias, fundações ou empresas públicas e sociedades de economia mista; e

III - no grau de reservado, das autoridades referidas nos incisos I e II e das que exerçam funções de direção, comando ou chefia, de acordo com regulamentação específica de cada órgão ou entidade, observado o disposto nesta Lei e na Lei Federal no 12.527, de 18 de novembro de 2011.

$\S 10$ A competência, prevista nos incisos I e II, no que se refere à classificação como ultrassecreta e secreta, poderá ser delegada pela autoridade responsável a agente público, vedada a subdelegação. (MARANHÃO, 2015, s.p.).

A lista de informações classificadas como sigilosas, no Executivo estadual, deverá ser encaminhada, no prazo de vinte dias, à Comissão Mista de Reavaliação de Informações e à Secretaria de Estado de Transparência e Controle. A divulgação das informações sigilosas deverá ser feita até o dia 31 de janeiro de cada ano pela internet e um extrato com a lista dessas informações, bem como a justificativa para tal classificação (art. 24), deverá ser disponibilizado impresso. 


\section{Considerações finais}

Pesquisas sobre a criação de leis de cunho federativo pressupõe um olhar voltado para o contexto em que são implementadas, como é o caso da LAI nos estados da região Nordeste. Vimos que essa implementação ocorreu, majoritariamente, em termos temporais, dentro do esperado, pois dos nove estados, cinco (Ceará, Sergipe, Bahia, Pernambuco e Paraíba) a regulamentaram no ano de 2012, quando a LAI nacional entrou em vigor; dois (Alagoas e Piauí) em 2013; e dois (Maranhão e Rio Grande do Norte) em 2015. Outro aspecto positivo é que essas LAI contemplam as transparências ativa e passiva, com a disponibilização, em alguns estados, de sites específicos, além da autoridade de monitoramento e autoridade de classificação. A regulamentação da LAI na região Nordeste, aponta para um compromisso legal dos governos de municiar a população para o exercício do direito de controle social das ações do poder público, o que, do nosso ponto de vista, é o início de uma reforma política no País, no momento em que a sociedade se articula e se mobiliza para participar da gestão pública.

No caso específico do Maranhão, marcado pelo déficit dos três anos que separam a entrada em vigor da LAI nacional e a criação da LAI estadual, trouxe à tona o rompimento com a continuidade de práticas políticas do grupo Sarney, incompatíveis com os valores democráticos. Como corolário disso, o Maranhão aderiu ao Programa Brasil Transparente da CGU, sinalizando compromisso com o rigor nas prestações de conta públicas e no combate à corrupção. A criação e a implementação da LAI nesse estado, imediatamente após a posse de um novo governador, parece emblemático da ruptura com uma tradição de interdição do controle social das ações administrativas do governo que o antecedeu. A LAI maranhense, nesse sentido, representa um avanço para um estado marcado por grandes desigualdades sociais e econômicas fruto - em grande parte - da ausência de canais que possibilitasse um diálogo aproximado da sociedade com o governo, bem como do acompanhamento e do controle da atuação da gestão pública. Inserir o Maranhão na agenda nacional de garantia do direito de acesso à informação representa um rompimento com as práticas de uma oligarquia política, ancorada há décadas no estado do Maranhão, cujas práticas de poder sempre foram marcadas pela vontade do sobrenome que o governava.

\section{Referências}

BARROS, D. S.; RODRIGUES, G. M. Os caminhos da (des)informação no jornal O Estado do Maranhão: o papel da mídia na divulgação da Lei de Acesso à Informação Pública. In: ENCONTRO NACIONAL DE PESQUISA EM CIÊNCIA DA INFORMAÇÃO, 14., Florianópolis, 2013. Anais... Florianópolis: ANCIB, 2013. Disponível em: $<$ http://enancib.sites.ufsc.br/index.php/enancib2013/XIVenancib/paper/viewFile/545/ 468>. Acesso em: 2 ago. 2015. 
BERTAZZI, D. M. O projeto de lei de acesso à informação e seu impacto sobre os servidores públicos. São Paulo: Artigo 19, 2011. p. 25-38. Disponível em: $<$ http://artigo19.org/doc/Estudos\%20em\%20Liberdade\%20de\%20Informa\%C3\%A7 \%C3\%A30\%201\%20(web).pdf>. Acesso em: 10 ago. 2012.

BONI, R. Fim do sigilo eterno de documentos pode 'abrir feridas', diz Sarney. G1, Rio de Janeiro, Política, 13 jun. 2011. Disponível em: $<$ http://g1.globo.com/politica/noticia/2011/06/fim-do-sigilo-eterno-de-documentos-pode-abrirferidas-diz-sarney.html . Acesso em: 20 ago. 2011.

BRASIL. Constituição (1988). Constituição da República Federativa do Brasil. Brasília, DF: Senado, 1988.

BRASIL. Presidência da República. Lei no 12.527 , de 18 de novembro de 2011. Regula o acesso a informações previsto no inciso XXXIII do art. $5^{\circ}$, no inciso II do $\S 3^{\circ}$ do art. 37 e no $\S 2^{\circ}$ do art. 216 da Constituição Federal; altera a Lei $\mathrm{n}^{\circ} 8.112$, de 11 de dezembro de 1990; revoga a Lei $\mathrm{n}^{\circ} 11.111$, de 5 de maio de 2005, e dispositivos da Lei $n^{\circ} 8.159$, de 8 de janeiro de 1991; e dá outras providências. Diário Oficial da União, Brasília, DF, 2011a. Disponível em: <http://www.planalto.gov.br/ccivil 03/ ato20112014/2011/lei/l12527.htm>. Acesso em: 20 nov. 2011.

BRASIL. Presidência da República. Lei no 12.528 , de 18 de novembro de 2011, que cria a Comissão Nacional da Verdade no âmbito da Casa Civil da Presidência da República. Diário Oficial da União, Brasília, DF, 2011b.Disponível em:

$<\quad$ http://www.planalto.gov.br/ccivil 03/ ato2011-2014/2011/lei/l12528.htm $>$. Acesso em: 12 jan. 2015.

BRASIL. Presidência da República. Decreto no 7.724, de 16 de maio de 2012. Regulamenta a Lei n. 12.527, de 18 de novembro de 2011, que dispõe sobre o acesso a informações previsto no inciso XXXIII do caput do art.50, no inciso II do $\S 2^{\circ}$ do art. 216 da Constituição. Diário Oficial da União, Brasília, DF, 2012.2 Disponível em: <http://www.planalto.gov.br/ccivil 03/ ato2011-2014/2012/decreto/d7724.htm>. Acesso em: 18 maio 2012.

BRASIL. Presidência da República. Decreto no 4.923 de 18 de dezembro de 2003. Dispõe sobre o Conselho de Transparência Pública e Combate à Corrupção, e dá outras providências. Diário Oficial da União, Brasília, DF, 2003. Disponível em: <http://www.planalto.gov.br/ccivil 03/decreto/2003/d4923.htm > Acesso em: 10 jan.2005.

BRASIL. Controladoria Geral da União. Programa Brasil Transparente ultrapassa marca de 1.500 adesões. Brasília, DF, 2015. Disponível em: <http://www.cgu.gov.br/assuntos/transparencia-publica/brasil-transparente $>$.

Acesso em: 16 set. 2015. 
BRASIL. Controladoria Geral da União. Ações e programas. Brasília, DF, 2014. Disponível em: <http://www.cgu.gov.br/sobre/acoes-e-programas>. Acesso em: 15 set. 2014.

BRASIL. Controladoria Geral da União. Ações e Programas. Brasília, DF, 2013. Disponível em: <http://www.cgu.gov.br/sobre/acoes-e-programas . Acesso em: 10 ago. 2015.

BRASIL. Câmara dos Deputados. Projeto de Lei PL 219/2003. Regulamenta o inciso XXXIII do art. $5^{\circ}$ da Constituição Federal, dispondo sobre prestação de informações detidas pelos órgãos da Administração Pública. Brasília, DF, 2003. Disponível em:

<http://www.camara.gov.br/proposicoesWeb/fichadetramitacao?idProposi cao $=434566>$. Acesso em: 10 jan. 2009.

BRASIL. Câmara dos Deputados. Projeto de Lei PL 5.228/2009. Regula o acesso a informações previsto no inciso XXXIII do art. $5^{\circ}$, inciso II do $\S 3^{\circ}$ do art. 37 e no $\S 20$ do art. 216 da Constituição, e dá outras providências. Brasília, DF, 2009. Disponível em: <http://www2.camara.leg.br/proposicoesWeb/fichadetramitacao?idPropos icao=1052 37>. Acesso em: 10 jan. 2009.

BRASIL. Câmara dos Deputados. Projeto de Lei PL 41/2010. Regula o acesso a informações previsto no inciso XXXIII do art. $5^{\circ}$, no inciso II do $\S$ $3^{\circ}$ do art. 37 e no $\S 2^{\circ}$ do art. 216 da Constituição Federal; altera a Lei no 8.112, de 11 de dezembro de 1990; revoga a Lei no 11.111 , de 5 de maio de 2005, e dispositivos da Lei no 8.159, de 8 de janeiro de 1991; e dá outras providências. Brasília, DF, 2010. Disponível em: < https://www25.senado.leg.br/web/atividade/materias/-/materia/96674>. Acesso em: 12 maio 2010.

CUNHA FILHO, M. C.; XAVIER, V. C. S. Lei de acesso à informação: teoria e prática. Rio de Janeiro: Lumen Jurís, 2014.

INSTITUTO BRASILEIRO DE GEOGRAFIA E ESTATÍSTICA (IBGE). Estimativas da população residente no Brasil e unidades da federação com data de referência em $1^{0}$ de julho de 2014. Brasília, DF, 2014. Disponível em:

<http://ftp.ibge.gov.br/Estimativas_de_Populacao/Estimativas_2014/esti mativa_dou_2014.pdf>. Acesso em: 10 ago. 2015.

INSTITUTO BRASILEIRO DE GEOGRAFIA E ESTATÍSTICA (IBGE). Pnad 2013: Internet pelo celular é utilizada em mais da metade dos domicílios que acessam a Rede. [Brasília, DF], 2015. Disponível em: $<$ https://agenciadenoticias.ibge.gov.br/agencia-noticias/2013-agencia-de-

noticias/releases/9840-pnad-2013-internet-pelo-celular-e-utilizada-em-mais-dametade-dos-domicilios-que-acessam-a-rede.html>. Acesso em: 30 abr. 2015.

INDOLFO, A. C. O acesso às informações públicas: retrocessos e avanços da legislação brasileira. Informação Arquivística, Rio de Janeiro, v. 2, n. 1, p. 4-23, jan./jun., $2013 . \quad$ Disponível 
em: $<\underline{w w w . a a e r j . o r g . b r / o j s / i n d e x . p h p / i n f o r m a c a o a r q u i v i s t i c a / a r t i c l e / . . . / 10 ~}>$. Acesso em: 20 nov.2013.

JARDIM, J. M. A implantação da lei de acesso à informação pública e a gestão da informação arquivística governamental. Liinc em Revista, Rio de Janeiro, v. 9, n. 2, p. 383-405, novembro 2013. Disponível em: <http://revista.ibict.br/liinc/index.php/liinc/article/viewFile/639/439>. Acesso em: 15 dez. 2013.

MADEIRA, J. Deputados não se entendem e Assembleia segue improdutiva. São Luís, 2014. Disponível em: $<$ http://blogdojardsonmadeira.com.br/deputados-nao-se-entendem-e-assembleiasegue-improdutiva/>. Acesso em: 15 ago. 2015.

MARANHÃO. Secretaria de Transparência e Controle. Lei no 10.217, de 23 de março de 2015. Dispõe sobre regras específicas para garantir o acesso a informações no âmbito do Estado do Maranhão, altera a Lei no 6.107, de 27 de julho de 1994, e dá outras providências. São Luís, 2015. Disponível em: <http://www.stc.ma.gov.br/legisla-documento/?id=3809>. Acesso em: 25 mar. 2015.

MARANHÃO. Mensagem 075/2014. Diário da Assembleia, São Luís, 22 out. 2014. Disponível em: <http://www.al.ma.leg.br/diarios/arquivos/221020141468753316diario.pdf>. Acesso em: 24 out. 2014.

MARANHÃO. Mensagem 034/2015. Diário da Assembleia, São Luís, 17 mar. 2015. Disponível em: <http://www.al.ma.leg.br/diarios/arquivos/170320151721766717diario.pdf>. Acesso em: 20 mar. 2015.

MARANHÃO. Assembleia Legislativa. Projeto de Lei PL 040/2015. Dispõe sobre regras específicas para garantir o acesso a informações no âmbito do Estado do Maranhão, altera a Lei n o 6.107, de 27 de julho de 1994, e dá outras providências. Diário da Assembleia, São Luís, 17 mar. 2015. Disponível em: <http://www.al.ma.leg.br/diarios/arquivos/170320151721766717diario.pdf. $>$ Acesso em: 20 mar.2015.

MARANHÃO. Mensagem 035/2014. Diário da Assembleia, São Luís, 22 out. 2014. Disponível em: <http://www.al.ma.leg.br/diarios/arquivos/221020141468753316diario.pdf>. Acesso em: 24 out.2014

MARANHÃO. Assembleia Legislativa. Projeto de Lei PL 200/2014. Dispõe sobre o acesso à informação no âmbito do Estado do Maranhão e dá outras providências. São Luís, 2014. Disponível em: < http://www.al.ma.leg.br/diarios/arquivos/22102014-1468753316diario.pdf>. Acesso em: 24 out. 2014.

MENDEL, Toby. Liberdade de expressão: um estudo de direito comparado. Brasília, DF: 2009.

MOREIRA, H. S.; CASSIANO, S.; SCHMIDT, C. A Implantação da Lei de Acesso à Informação nos Estados Brasileiros. In: CONGRESSO BRASILEIRO DE CIÊNCIAS DA COMUNICAÇÃO, 37., Foz do Iguaçu, 2014. Anais... Foz do Iguaçu: Intercom, 2014. Disponível em: 
$<$ https://mail.google.com/mail/u/0/\#search/georgete/1504e16b5d292b48?projector=1 $>$. Acesso em: 5 jan. 2015.

NUNES, M. T. G. Lei de acesso à informação: reconstrução da verdade histórica, ambientes regulatórios e o direito à intimidade. São Paulo: Quartier Latin, 2014.

RODRIGUES, G. M. Indicadores de "transparência ativa" em instituições públicas: análise dos portais de universidades públicas federais. Liinc em Revista, Rio de Janeiro, v. 9, n. 2, p. 423-438, nov. 2013. Disponível em: $<$ http://revista.ibict.br/liinc/index.php/liinc/article/viewFile/616/441/>. Acesso em: 10 nov. 2013.

RODRIGUES, G. M. Legislação de acesso aos arquivos no Brasil: um terreno de disputas políticas pela memória e pela história. Acervo, Rio de Janeiro, v. 24, n. 1, p. 257-286, jan./jun. 2011. Disponível em: $<$ http://pfdc.pgr.mpf.mp.br/atuacao-e-conteudos-de-apoio/publicacoes/acesso-ainformacao/legislacao-de-acessoaos-arquivos-no-brasil-um-terreno-de-disputaspoliticas-pela-memoria-e-pela-historia-georgete-medleg-rodrigues/view>. Acesso em: 2 dez. 2011.

ROUSSEFF, D. Discurso proferido pela presidenta da República, Dilma Rousseff, na solenidade de sanção do projeto Lei que garante o acesso à informação pública e ao projeto Lei que cria a Comissão Nacional da Verdade, no Palácio do Planalto no dia 18 de novembro de 2011. Brasília, DF, 2011. Disponível em: <http://www2.planalto.gov.br/acompanhe-oplanalto/discursos/discursos-da-presidenta/discurso-da-presidenta-da-republicadilma-rousseff-durante-cerimonia-de-sancao-do-projeto-de-lei-que-garante-o-acessoa-informacoes-publicas-e-do-projeto-de-lei-que-cria-a-comissao-nacional-daverdade $>$. Acesso em: 20 nov. 2011.

SALES, R. G. O direito de acesso à informação pública administrativa. Rio de Janeiro: Lumen Juris, 2014. 